ARTICLE

https://doi.org/10.1038/s41467-022-27979-5

\title{
Stratification constrains future heat and carbon uptake in the Southern Ocean between $30^{\circ} \mathrm{S}$ and $55^{\circ} \mathrm{S}$
}

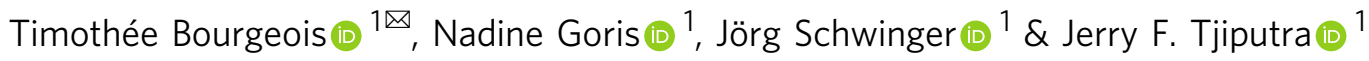

The Southern Ocean between $30^{\circ} \mathrm{S}$ and $55^{\circ} \mathrm{S}$ is a major sink of excess heat and anthropogenic carbon, but model projections of these sinks remain highly uncertain. Reducing such uncertainties is required to effectively guide the development of climate mitigation policies for meeting the ambitious climate targets of the Paris Agreement. Here, we show that the large spread in the projections of future excess heat uptake efficiency and cumulative anthropogenic carbon uptake in this region are strongly linked to the models' contemporary stratification. This relationship is robust across two generations of Earth system models and is used to reduce the uncertainty of future estimates of the cumulative anthropogenic carbon uptake by up to $53 \%$ and the excess heat uptake efficiency by $28 \%$. Our results highlight that, for this region, an improved representation of stratification in Earth system models is key to constrain future carbon budgets and climate change projections. 
T he Southern Ocean is a dynamically complex region. The strong wind-driven Antarctic Circumpolar Current drives a residual overturning circulation, consisting of an upwelling of circumpolar deep waters around the Polar Front, a residual northward transport with gradual water mass transformation to Antarctic Intermediate and Mode Waters (IW and MW), and finally subduction under subtropical waters. The upwelled water mass is cold and undersaturated with respect to anthropogenic carbon, allowing it to efficiently absorb large amounts of atmospheric excess heat and anthropogenic carbon $^{1-3}$. Therefore, the subduction of IW and MW masses, occurring approximately between $30^{\circ} \mathrm{S}$ and $55^{\circ} \mathrm{S}$, provides one of the major gateways carrying anthropogenic carbon $\left(\mathrm{C}_{\mathrm{ant}}\right)$ and excess heat $\left(\mathrm{H}_{\text {excess }}\right)$ into the interior ocean (e.g. refs. $\left.{ }^{4-7}\right)$, where they stay isolated from the atmosphere on decadal to millennial timescales ${ }^{8,9}$. For the historical period from 1850 to 2005, it has been estimated that $43 \%$ of $\mathrm{C}_{\text {ant }}$ and $75 \%$ of $\mathrm{H}_{\text {excess }}$ have entered the ocean south of $30^{\circ} \mathrm{S}^{10}$, although the Southern Ocean accounts for only $30 \%$ of the total ocean surface area. Over the same period, the region between $30^{\circ} \mathrm{S}$ and $55^{\circ} \mathrm{S}$ is responsible for 27 and $50 \%$ of the global ocean $\mathrm{C}_{\text {ant }}$ and $\mathrm{H}_{\text {excess }}$ uptake despite covering only $21 \%$ of the world ocean, according to the models analysed in this study.

Future projections of $\mathrm{C}_{\text {ant }}$ and $\mathrm{H}_{\text {excess }}$ uptake in the region between $30^{\circ} \mathrm{S}$ and $55^{\circ} \mathrm{S}$ from the last two generations Earth system models (ESMs) remain uncertain ${ }^{11,12}$ (Fig. 1) because ESMs struggle to capture the complex dynamical and biogeochemical processes in this region ${ }^{13-15}$. Despite improvements in model performance in successive phases of the Coupled Model Intercomparison Project (CMIP), this progress might be too slow to warrant significantly reduced uncertainty of ESM projections within the next decade ${ }^{16}$. Since this is the time horizon for framing climate mitigation policies that allow for meeting stringent climate targets ${ }^{17,18}$, more efforts have to be put into model analysis, i.e., understanding the roots of this uncertainty and reducing uncertainty in key climate metrics such as the projected carbon and heat uptake. The technique of emergent constraints provides a means to constrain a model ensemble through an emergent strong statistical relationship between an observable quantity of current climate and future changes in a variable of interest ${ }^{19,20}$. It has been used to constrain several aspects of the terrestrial $^{21-23}$ and marine ${ }^{24-26}$ carbon cycle.

In this work, we identify a key mechanism that explains the large inter model-uncertainty in future projections of $\mathrm{H}_{\text {excess }}$ and $\mathrm{C}_{\text {ant }}$ uptake between $30^{\circ} \mathrm{S}$ and $55^{\circ} \mathrm{S}$ across both CMIP5 and
CMIP6 ESMs. We focus on the region between $30^{\circ} \mathrm{S}$ and $55^{\circ} \mathrm{S}$ since this is the area where intermediate and mode waters are formed and subducted (Methods). We find that the climatological stratification state in this region is tightly related to this subduction and we use this finding to robustly constrain both future $\mathrm{H}_{\text {excess }}$ and $\mathrm{C}_{\text {ant }}$ uptake. We note that our definition of $\mathrm{C}_{\text {ant }}$ and $\mathrm{H}_{\text {excess }}$ includes changes induced by climate change such as changes in ocean circulation, wind conditions and primary production (Methods).

\section{Results}

Linking stratification to oceanic $\mathrm{C}_{\text {ant }}$ and $\mathbf{H}_{\text {excess }}$ uptake. We find that stratification biases in CMIP5 and CMIP6 ESMs in the region between $30^{\circ} \mathrm{S}$ and $55^{\circ} \mathrm{S}$ are strongly related to the amount of their future uptake of excess heat per degree of transient global warming $\left(\mathrm{H}_{\text {excess }}\right.$ uptake efficiency) and anthropogenic carbon (Fig. 2). Models showing a positive density bias that increases with depth relative to the surface bias (indicating stronger-thanobserved stratification) tend to simulate a low uptake of $\mathrm{C}_{\text {ant }}$ and low $\mathrm{H}_{\text {excess }}$ uptake efficiency. The opposite is true for models that show an increasingly negative density bias profile relative to their surface bias (indicating weaker-than-observed stratification).

In order to develop an emergent constraint from this apparent relationship, we need to capture the characteristics of the vertical structure of these density profiles in one metric. To this end, we use a stratification index ${ }^{27}$, which is the cumulative sum of density differences with respect to surface density (Methods), here applied over the upper $2000 \mathrm{~m}$ of the water column. This depth range has been chosen as it encompasses the MW and IW formation and subduction pathways in CMIP $\mathrm{ESMs}^{7,28}$, and modern observational coverage is good, since it is covered by standard ARGO floats.

We identify the core of IW in each ESM by determining the depth of the salinity minimum at $30^{\circ} \mathrm{S}$ (ref. ${ }^{28}$ ), and we find that the stratification index is highly correlated to both (1) the depth at which IW are subducted $(\mathrm{R}=-0.83)$ and (2) the subducted volume of IW and overlying $\mathrm{MW}(\mathrm{R}=-0.77$, both shown in Supplementary Fig. 1). Therefore, consistent with a previous study $^{29}$, we find that the modelled volume of MW and IW formation is of high importance for determining the efficiency of $\mathrm{C}_{\mathrm{ant}}$ and $\mathrm{H}_{\text {excess }}$ sequestration. However, the stratification index has the clear advantage of being straightforward to estimate from model output while the identification of water masses is more challenging and model-dependent ${ }^{28}$. (a)

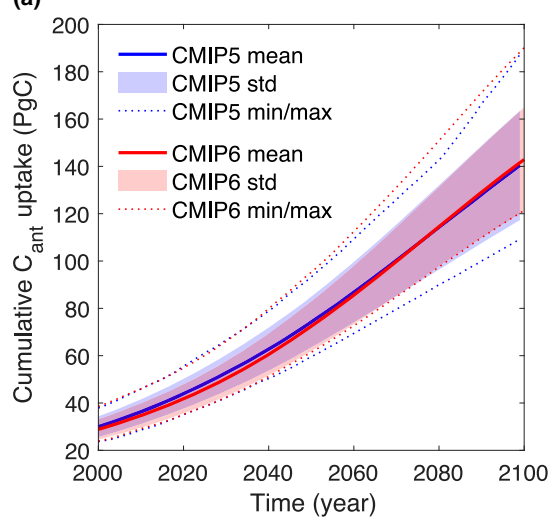

(b)

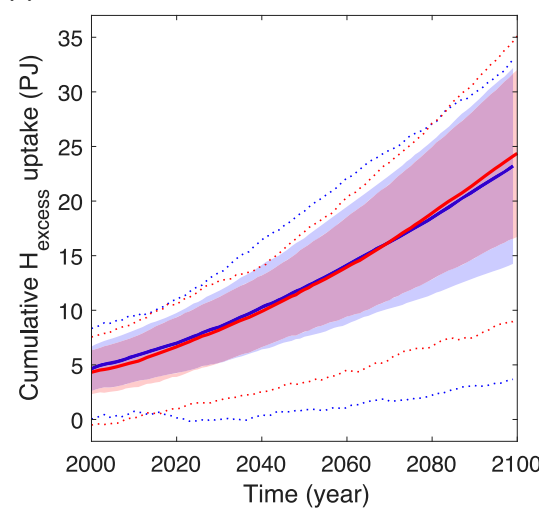

(c)

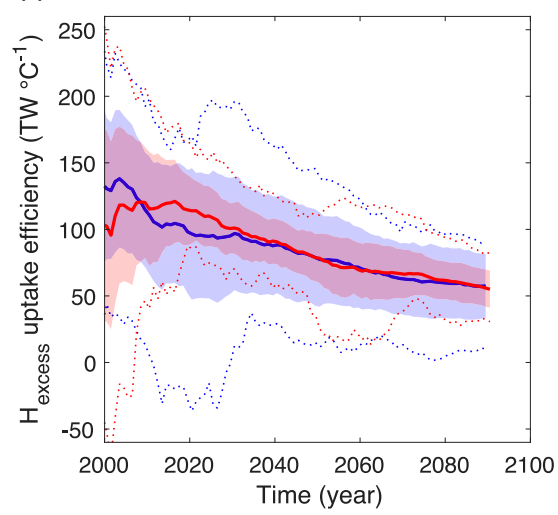

Fig. 1 Projections of carbon and heat uptake in the Southern Ocean (30 $\left.{ }^{\circ} \mathbf{S}-\mathbf{5 5} 5^{\circ} \mathbf{S}\right)$. Southern Ocean $\left(30^{\circ} \mathrm{S}-55^{\circ} \mathrm{S}\right)$ a cumulative $\mathrm{C}_{\mathrm{ant}}$ uptake, $\mathbf{b}$ cumulative $\mathrm{H}_{\text {excess }}$ uptake and $\mathbf{c} \mathrm{H}_{\text {excess }}$ uptake efficiency, i.e. mean excess heat uptake per degree of global warming (Methods) averaged over $17 \mathrm{CMIP5}$ and 16 CMIP6 models (described in Supplementary Tables 1 and 2) for historical, RCP8.5 (CMIP5) and SSP5-8.5 (CMIP6) experiments. Shaded areas and dotted lines represent one standard deviation (std) and the minimum/maximum ( $\mathrm{min} / \mathrm{max}$ ) of the inter-model spread, respectively. 

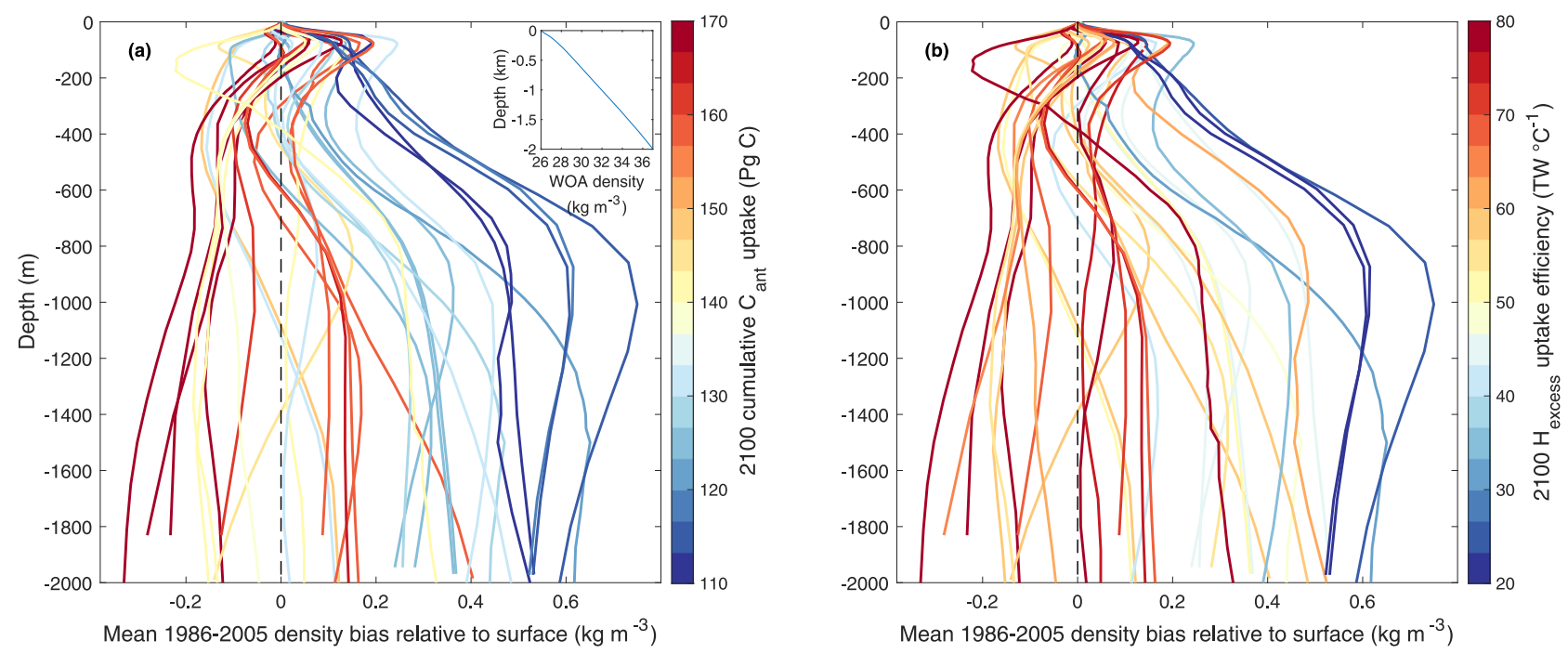

Fig. 2 Linkage between contemporary model density bias and projected future ocean carbon and heat uptake. Vertical profiles of Southern Ocean $\left(30^{\circ} \mathrm{S}-55^{\circ} \mathrm{S}\right)$ density bias $\left(\mathrm{kg} \mathrm{m}^{-3}\right)$ of CMIP5/6 models averaged over 1986-2005 relative to the density of the World Ocean Atlas 201354,55. The surface bias is subtracted from each profile, such that profiles start with a value of zero at the surface. Negative (positive) density bias relative to surface bias indicates weaker- (stronger-) than-observed stratification. Each line shows a single ESM and the colour indicates the magnitude of a cumulative $\mathrm{C}_{\text {ant }}$ uptake and $\mathbf{b} \mathrm{H}_{\text {excess }}$ uptake efficiency for the year 2100. The World Ocean Atlas (WOA) density profile is provided as an inset of panel (a).

We find that ESMs with high-stratification index and correspondingly low $\mathrm{C}_{\text {ant }}$ uptake typically simulate lower uptake in the region around $55^{\circ} \mathrm{S}$, but more importantly, the northward extent of their uptake is much more limited compared to models with low stratification index (Fig. 3). The latter models project accumulated uptake of more than $100 \mathrm{~mol} \mathrm{C} \mathrm{m}^{-2}$ in large regions north of $40^{\circ} \mathrm{S}$ in Pacific, Indian and Atlantic sectors, where low $\mathrm{C}_{\text {ant }}$-uptake models show uptake below $50 \mathrm{~mol} \mathrm{C} \mathrm{m}^{-2}$ (see also Supplementary Fig. 2 for a zonal mean view of $\mathrm{C}_{\text {ant }}$ uptake and Supplementary Fig. 3 for an equivalent to Fig. 3 but for CMIP6 models). The higher (lower) $\mathrm{C}_{\text {ant }}$ uptake simulated by ESMs with low (high) stratification index is connected to a steeper (shallower) surface-to-depth gradient of the anthropogenic component of dissolved inorganic carbon $\left(\mathrm{DIC}_{\mathrm{ant}}\right)$ concentration along the vertical zonal mean section between $30^{\circ} \mathrm{S}$ and $55^{\circ} \mathrm{S}$ (Fig. 3c, d). A similar surface-to-depth feature can also be seen in the warming efficiency (Fig. 3e, f).

It is physically plausible for a model that exhibits a stronger stratification than observed to take up less carbon and heat than a model with weaker than observed stratification. However, the fact that present-day stratification is related to projected future uptakes across our model ensemble is not obvious, since stratification is changing with progressing climate change. We find that, in the region between $30^{\circ} \mathrm{S}$ and $55^{\circ} \mathrm{S}$, the projected stratification bias of models relative to each other remains largely unchanged, i.e., a model that simulates a stronger contemporary stratification than the multi-model mean will do so for future time periods, too. The correlation between the mean present-day (1986-2005) stratification index and the mean future (2080-2099) stratification index is 0.91 (Supplementary Fig. 4).

The target variables for our constraints are (i) the cumulative ocean $\mathrm{C}_{\text {ant }}$ uptake $[\mathrm{PgC}]$ as this minimises interannual and decadal variability (compared to annual carbon fluxes) while preserving trends and (ii) the 20-year average of ocean $\mathrm{H}_{\text {excess }}$ uptake efficiency $\left[\mathrm{TW}{ }^{\circ} \mathrm{C}^{-1}\right.$ ] defined as the ratio between ocean $\mathrm{H}_{\text {excess }}$ uptake rate $[\mathrm{TW}]$ and global atmospheric surface warming $\left[{ }^{\circ} \mathrm{C}\right]\left(\right.$ ref. $\left.{ }^{30}\right)$. The latter choice is motivated by the fact that the simulated atmospheric surface temperature that forces the oceanic heat uptake rates depends on each model's response to radiative forcing. We, therefore, normalise the excess heat uptake by global surface warming ${ }^{31-33}$. Additional information on the validity of our findings for the $\mathrm{H}_{\text {excess }}$ uptake rate [TW] without normalisation are presented in the supplement (Supplementary Fig. 5).

In our analysis of $\mathrm{H}_{\text {excess }}$ uptake efficiency, we merge the CMIP5 and CMIP6 ensembles because both rely on scenarios with the same end of century radiative forcing (RCP8.5 and SSP58.5 , respectively). Such a merger is not meaningful for the $C_{a n t}$ uptake as the CMIP6 SSP5-8.5 scenario reaches considerably higher end-of-century atmospheric $\mathrm{CO}_{2}$ concentrations than the CMIP5 RCP8.5 scenario ${ }^{34}$. The radiative forcing due to higher $\mathrm{CO}_{2}$ concentrations in SSP5-8.5 is compensated by lower concentrations of other greenhouse gases, mainly methane and nitrous oxide.

Reducing uncertainties in ocean uptake projections. Significant negative correlations exist between the simulated present-day water-column stratification index and both cumulative $\mathrm{C}_{\text {ant }}$ uptake and $\mathrm{H}_{\text {excess }}$ uptake efficiency at the end of the century (Fig. $4 a-c)$. We note that the correlations between the stratification index and $\mathrm{H}_{\text {excess }}$ are still significant but less robust without normalising the $\mathrm{H}_{\text {excess }}$ uptake (Supplementary Fig. 5). These correlations indicate that a more stratified ocean absorbs less $\mathrm{C}_{\text {ant }}$ and $\mathrm{H}_{\text {excess }}$. For $\mathrm{C}_{\text {ant }}$ uptake, the high correlation with contemporary stratification is very stable over time (Fig. $4 \mathrm{~g}$ ), whereas for $\mathrm{H}_{\text {excess }}$ uptake efficiency the correlation is initially low but gets stronger with time (see Discussion) and reaches values of 0.7 $(P=0.003)$ for CMIP5 and $0.8(P<0.001)$ for CMIP6 at the end of the century (Fig. 4h). The WOA13-based stratification index and its uncertainty are estimated as $64.08 \pm 0.58 \mathrm{~kg} \mathrm{~m}^{-3}$ (Methods). This value is close to the CMIP5 and CMIP6 ensemble mean of $64.72 \pm 3.80 \mathrm{~kg} \mathrm{~m}^{-3}$ and $65.02 \pm 1.70 \mathrm{~kg} \mathrm{~m}^{-3}$, respectively. However, the model spread around the mean is substantial for both CMIP5 and CMIP6, with CMIP5 having a model uncertainty that is more than twice as large as the one of CMIP6.

Based on the high correlations for both the CMIP5 and CMIP6 ensembles, we apply the emergent constraint approach (Methods) to constrain the uncertainty in future projections of $\mathrm{C}_{\text {ant }}$ uptake and $\mathrm{H}_{\text {excess }}$ uptake efficiency. We assume that all models are independent as done in other studies ${ }^{35}$. We note that 
(a)

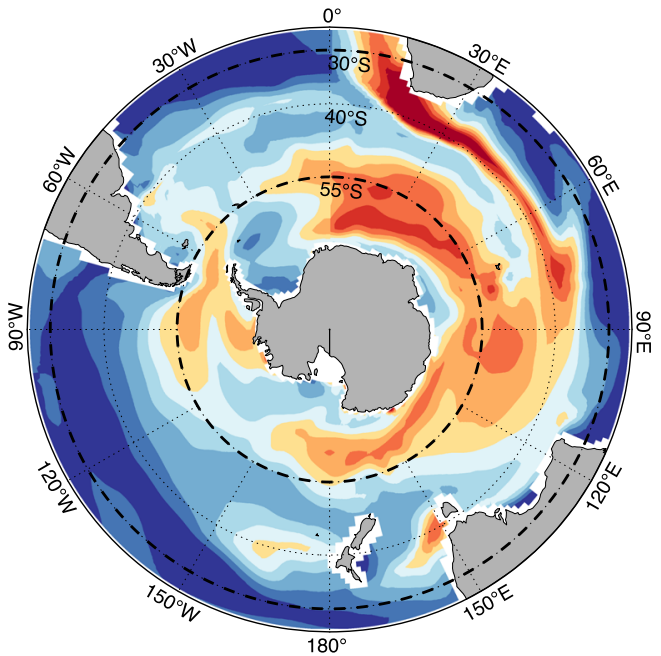

(c)

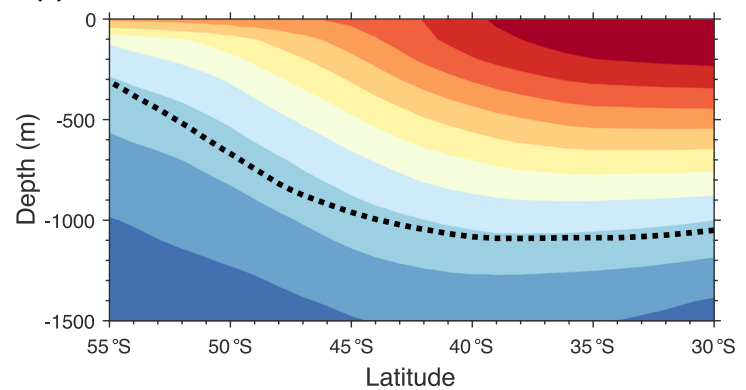

(e)

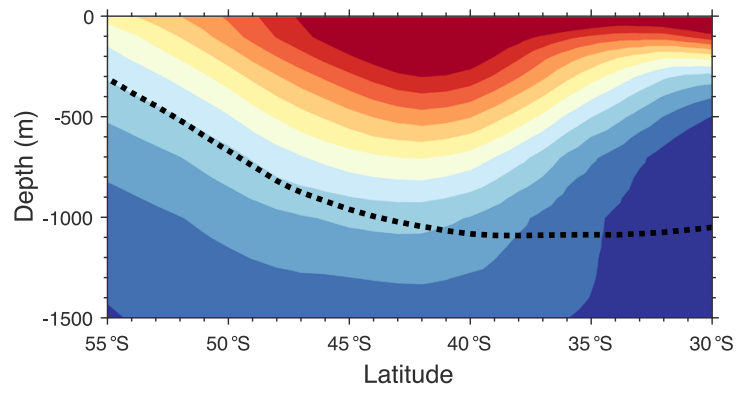

(b)
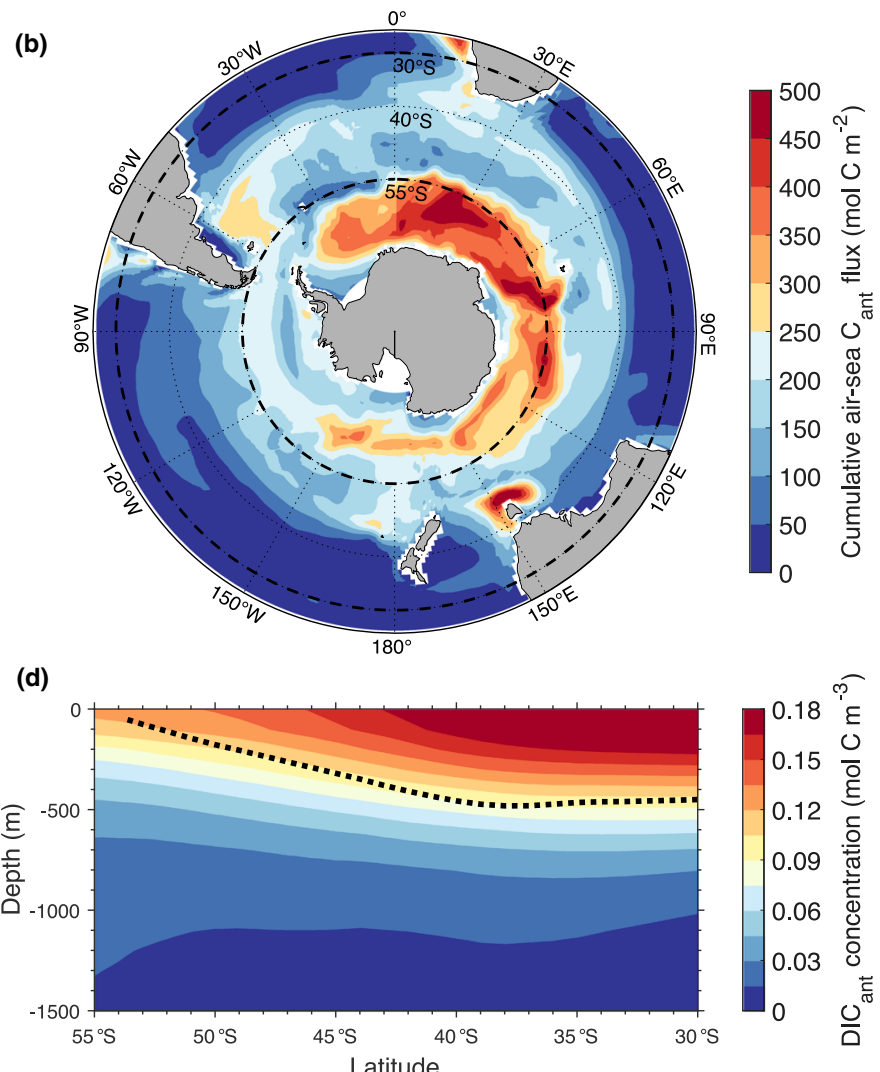

(f)

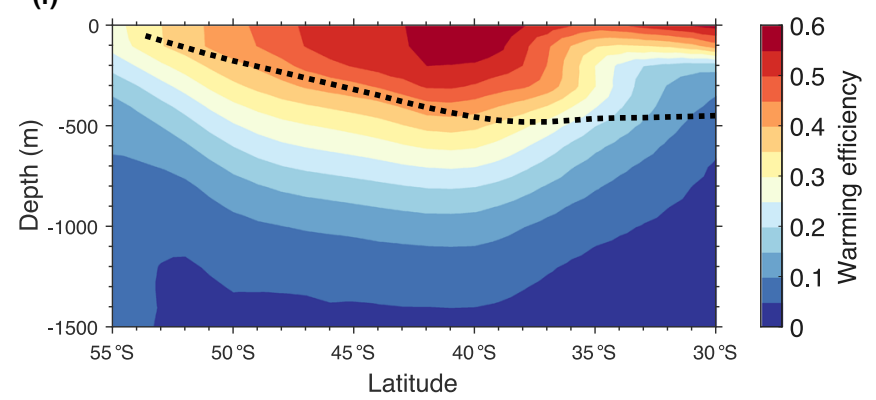

Fig. 3 Surface and interior distribution of carbon and heat for models with contrasting stratification states. a, b Model-mean of the 1850-2100 cumulative $C_{\text {ant }}$ uptake for scenario RCP8.5 from a the three lowest-stratification-index CMIP5 models (CMCC-CESM, IPSL-CM5A-LR and IPSL-CM5A$M R$ ) and $\mathbf{b}$ the three highest-stratification-index CMIP5 models (GFDL-ESM2G, HadGEM2-CC and HadGEM2-ES). Black dashed lines show the boundaries of our Southern-Ocean region $\left(30^{\circ} \mathrm{S}-55^{\circ} \mathrm{S}\right)$. c-f Corresponding zonally-averaged transects from the $\mathbf{c}$, e low- and $\mathbf{d}$, $\mathbf{f}$ high-stratification models for dissolved inorganic $C_{\text {ant }}$ concentration and warming efficiency. The latter is defined as the ratio between the transient minus piControl temperature anomaly and the global surface atmospheric warming. The black dotted lines in panels c-f represent the zonally averaged density isolines crossing the depth of the salinity minimum at $30^{\circ} \mathrm{S}^{28}$. See Supplementary Fig. 2 for the corresponding CMIP6 models.

this is a limitation of our study as some of these ESMs share components and code. Likewise, many CMIP6 models have been developed starting from their predecessor CMIP5 models such that the two ensembles are not entirely independent. An alternative approach could be based on an adaptive model weighting scheme or an ensemble reduction ${ }^{36,37}$, but this is beyond the scope of our study. After applying the observational constraint (Methods), the uncertainties of the cumulative $\mathrm{C}_{\text {ant }}$ uptake between $30^{\circ} \mathrm{S}$ and $55^{\circ} \mathrm{S}$ are considerably reduced by 53 and $32 \%$ for CMIP5 and CMIP6, respectively. The associated best estimate of cumulative $\mathrm{C}_{\text {ant }}$ uptake increases by 3 and $6 \%$ for CMIP5 and CMIP6 respectively compared to the prior-constraint estimate (Table 1). Similarly, the after-constraint uncertainty of $\mathrm{H}_{\text {excess }}$ uptake efficiency for the combined CMIP5/CMIP6 ensemble is strongly reduced by $28 \%$ and the associated estimate increases by $7 \%$.

\section{Discussion}

Our emergent constraint identifies a strong link between contemporary stratification in CMIP5/6 models and their ability to continuously take up $\mathrm{C}_{\text {ant }}$ and $\mathrm{H}_{\text {excess }}$ under a high- $\mathrm{CO}_{2}$ future scenario in the Southern Ocean between $30^{\circ} \mathrm{S}$ and $55^{\circ} \mathrm{S}$. The ESMs' stratification index correlates strongly with (i) the simulated depth at which the IW (and the overlying MW) are subducted and (ii) the simulated subducted water volume, here loosely referred to as the volume above the IW core (both shown in Supplementary Fig. 1). This suggests that a deeper position of the IW core is accompanied by a larger subduction volume, and hence a more efficient $\mathrm{C}_{\text {ant }}$ and $\mathrm{H}_{\text {excess }}$ sequestration in our model ensemble. This importance of the volume of ventilated waters for future $\mathrm{C}_{\mathrm{ant}}$ uptake in the Southern Ocean has been found in an independent study ${ }^{29}$. We note that the relationship between contemporary stratification and $\mathrm{C}_{\text {ant }}$ and $\mathrm{H}_{\text {excess }}$ uptake worsens 

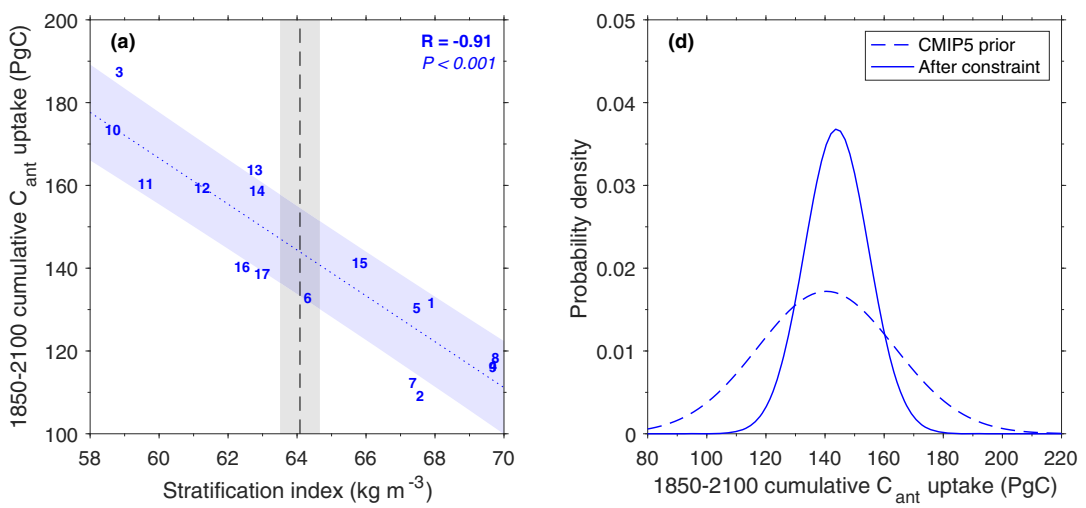

\begin{tabular}{|c|c|c|c|}
\hline-- & $\begin{array}{l}\text { WOA } 2013 \\
\text { Combined } 68 \% \text { pred. int. }\end{array}$ & & $\begin{array}{l}\text { Obs. std. } \\
\text { CMIP5 } 68 \% \text { pred. int. }\end{array}$ \\
\hline & CMIP6 $68 \%$ pred. int. & 1 & CanESM2 \\
\hline 1 & ACCESS-ESM1-5 & 2 & CESM1-BGC \\
\hline 2 & CanESM5 & 3 & CMCC-CESM \\
\hline 3 & CanESM5-CanOE & 4 & GFDL-ESM2G \\
\hline 4 & CESM2 & 5 & GFDL-ESM2M \\
\hline 5 & CESM2-WACCM & 6 & GISS-E2-R-CC \\
\hline 6 & CNRM-ESM2-1 & 7 & GISS-E2-H-CC \\
\hline 7 & GFDL-CM4 & 8 & HadGEM2-CC \\
\hline 8 & GFDL-ESM4 & 9 & HadGEM2-ES \\
\hline 9 & IPSL-CM6A-LR & 10 & IPSL-CM5A-LR \\
\hline 10 & MIROC-ES2L & 11 & IPSL-CM5A-MR \\
\hline 11 & MPI-ESM1-2-HR & 12 & IPSL-CM5B-LR \\
\hline 12 & MPI-ESM1-2-LR & 13 & MIROC-ESM \\
\hline 13 & MRI-ESM2-0 & 14 & MIROC-ESM-CHEM \\
\hline 14 & NorESM2-LM & 15 & NorESM1-ME \\
\hline 15 & NorESM2-MM & 16 & MPI-ESM-LR \\
\hline 16 & UKESM1-0-LL & 17 & MPI-ESM-MR \\
\hline
\end{tabular}
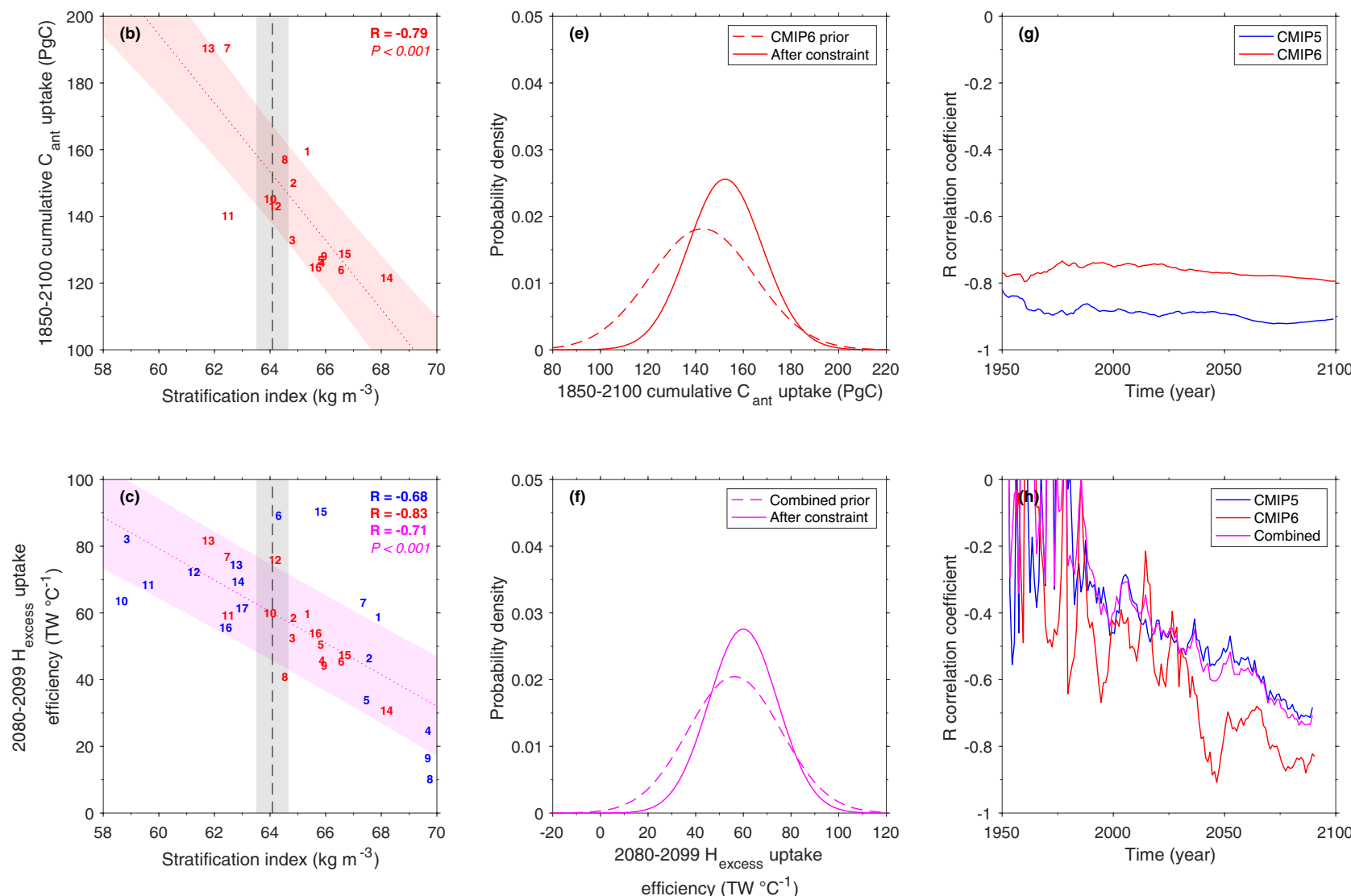

Fig. 4 Emergent constraints on the sensitivity of projected carbon and heat uptake to stratification. $\mathbf{a}, \mathbf{b}$ cumulative future $\mathrm{C}_{\mathrm{ant}}$ uptake between $30^{\circ} \mathrm{S}$ and $55^{\circ} \mathrm{S}$ and $\mathbf{c}$ future ocean $\mathrm{H}_{\text {excess }}$ uptake efficiency and their emergent relation to the contemporary stratification. CMIP5, CMIP6 and combined CMIP5/ 6 ensembles are denoted in blue, red and magenta, respectively. Emergent constraints include a linear regression fit (dotted line), its $68 \%$ prediction interval (abbreviated pred. int., coloured shaded area according to the ensemble), the observational constraint (vertical black dots) and its uncertainty (grey shaded area). All emergent constraints are accompanied by $\mathbf{d}-\mathbf{f}$ prior- and after-constraint probability density functions and $\mathbf{g}$, $\mathbf{h}$ correlation timeseries obtained by sliding the predictand over time while leaving the predictor fixed.

Table $1 \mathrm{~A}$ prior and revised estimates of future carbon and heat uptake. Prior- and after-constraint estimates and uncertainties (expressed as model mean and standard deviation) of the CMIP5, CMIP6 and combined ensemble in the Southern Ocean $\left(30^{\circ} \mathrm{S}-55^{\circ} \mathrm{S}\right)$ of cumulative $\mathrm{C}_{\mathrm{ant}}$ uptake $(\mathrm{Pg} \mathrm{C})$ and $\mathrm{H}_{\text {excess }}$ uptake efficiency $\left(\mathrm{TW}{ }^{\circ} \mathrm{C}^{-1}\right)$.

\section{Variable}

$\boldsymbol{\Sigma} C_{\text {ant }}(P g C)$

$\boldsymbol{\Sigma} C_{\text {ant }}(P g C)$

$\mathrm{H}_{\text {excess }}$ Eff. $\left(\mathrm{TW}^{\circ} \mathrm{C}^{-1}\right)$

Ensemble

CMIP5

CMIP6

Combined

Prior-constraint

$140 \pm 23$
$143 \pm 22$
$56 \pm 20$

After-constraint

$144 \pm 11$
$152 \pm 15$
$60 \pm 14$

Uncertainty change

$-53 \%$

$-32 \%$

$-28 \%$

Uncertainty changes between prior- and after-constraint are given in \%. Abbreviations are included for cumulative $(\boldsymbol{\Sigma})$ and efficiency (Eff.) 
when extending the region of interest south of $55^{\circ} \mathrm{S}$ and outside of the area of IW and MW subduction. Here, the $\mathrm{C}_{\text {ant }}$ and $\mathrm{H}_{\text {excess }}$ uptake is sensitive to other processes, such as sea-ice dynamics and bottom-water formation at the southward limb of Southern Ocean overturning circulation, and we find no direct link to the contemporary stratification (Supplementary Fig. 6).

It has been shown before that formation of mode and intermediate waters is key for carbon and heat uptake $e^{5,38}$, and that this water mass formation appears to be linked to the simulated winter mixed layer depths of CMIP5 models ${ }^{14}$. We find, however, that the relationship between future cumulative $\mathrm{C}_{\text {ant }}$ and $\mathrm{H}_{\text {excess }}$ uptake efficiency and mixed layer depth in our region is only weak. There is no significant correlation between annual mean or maximum winter mixed layer depth and carbon and heat uptakes (Supplementary Figs. 7, 8). Deep winter mixing in our region is thought to be the main contributor to carbon and heat subduction, and therefore such relatively low correlations might seem surprising. A previous study ${ }^{14}$ has shown that stratification biases in ESMs contribute to setting the maximum winter mixed layer depth, and this effect is also captured by our constraint. In addition, other processes (such as diapycnal mixing and Ekman pumping) are also important for the eventual subduction of carbon and heat away from the seasonally varying base of the mixed layer ${ }^{39,40}$. A robust relationship can be found when taking the stratification of the upper $2000 \mathrm{~m}$ of the water column into account, but we note that our constraint is not sensitive to the exact lower bound of this depth range when it is varied between 1000 and $2000 \mathrm{~m}$. We translate these findings into a physically plausible and robust emergent constraint for future projections of two generations of ESMs. It provides us with the unique possibility to constrain the model uncertainty for two highly important quantities at the same time.

For the CMIP5/6 generation of models, we find that the simulated contemporary stratification between $30^{\circ} \mathrm{S}$ and $55^{\circ} \mathrm{S}$ is highly correlated to its projected future values across CMIP5/6 ( R correlation of 0.91 ). Models with a strong stratification store more of the excess heat in the upper ocean, thereby creating stronger stratification changes, while the opposite is true for weakly stratified models ${ }^{41}$. This mechanistic explanation suggests that ESMs that simulate a realistic contemporary density profile are more reliable in simulating future density profiles. The predictor of our emergent constraint, i.e. the contemporary stratification, hence also constrains the future stratification and, as demonstrated here, the future cumulative $\mathrm{C}_{\text {ant }}$ uptake and the $\mathrm{H}_{\text {excess }}$ uptake efficiency. A recent study indicates that projected patterns of heat storage are primarily dictated by the preindustrial ocean circulation ${ }^{42}$. Contemporary oceanic storage of anthropogenic carbon and excess heat have distinct patterns ${ }^{43-45}$ and redistributed heat and carbon are projected to have opposing signs, leading to a more horizontal structure of heat storage than seen in the patterns of carbon storage in the Southern Ocean ${ }^{46}$. However, these differences are reduced in future projections of the Southern Ocean as the spatially averaged added heat becomes dominant over the redistribution of heat due to circulation changes ${ }^{42,46}$. This is consistent with our findings, specifically with the initially low but increasing correlation between stratification and excess heat uptake efficiency (Fig. 4e). We note that other quantities like the nutrient cycle and primary productivity are also closely linked to stratification, e.g. it has been shown that CMIP5 models with a stronger bias in contemporary surface stratification tend to predict larger climate-induced declines in surface nutrients and net primary production ${ }^{47}$. Due to the high importance of contemporary stratification biases for future marine projections, it is essential to reduce them.
Our results identify significant stratification biases for most CMIP5/6 models in the areas of MW and IW formation, but also that the representation of stratification in the Southern Ocean between $30^{\circ} \mathrm{S}$ and $55^{\circ} \mathrm{S}$ has improved between CMIP5 and CMIP6. In fully coupled ESMs, it remains difficult to identify the ultimate source of biases. The emergent-constraint method is only able to identify systematic biases associated with the variables used in the emergent-constraint relationships. It does not highlight missing processes or dynamical biases common in ESMs which are not directly related to the observable processes or variables used in the constrained process ${ }^{35,37,48}$. As many of the model biases in the Southern Ocean temperature and salinity structure are concentrated in recently ventilated layers or in the deep Atlantic, they appear to stem from inaccuracies in the North Atlantic Deep Water formation regions or in the surface climate over the Southern Ocean ${ }^{16}$. Recently, a strong emergent constraint relationship has been found between surface salinity and cumulative $C_{\text {ant }}$ uptake in the Southern Ocean ${ }^{49}$. In combination with our constraint, this indicates that surface salinity is a fundamental player setting the Southern Ocean stratification. Here, the upper ocean properties like salinity are highly sensitive to a multitude of uncertainties in the sea-ice, ocean, and atmosphere components of an ESM, e.g. westerly jet position, Antarctic seaice extent and its potential relation to precipitation, clouds, mixing and transport by eddies. It takes a tremendous effort to model or parameterise all these processes in a realistic manner and a significant reduction of bias is not to be expected within this decade ${ }^{16}$. For the ocean, it has been found that eddy-induced diffusion is an important factor in setting the simulated stratification $^{41}$. Hence, a better representation of eddies, be it through increased eddy-resolving resolution ${ }^{50}$ or through improved eddy parameterisations ${ }^{51}$ will very likely contribute to reducing stratification biases in ESMs. Future studies should elucidate processes that could contribute to the bias and large spread in the stratification index simulated across ESMs, for instance, our stratification index could be influenced by the water mass properties of the circumpolar deep water, which is formed in the North Atlantic. A better understanding of the linkage between North Atlantic climate representation and the SouthernOcean water-mass properties across ESMs could be valuable.

Ensembles of ESMs remain our only tool at hand to investigate the response of the Earth system to future scenarios of anthropogenic forcing. Reducing the large uncertainties arising from, among others, the representation of Southern Ocean dynamics in these models remains a challenge. The identification of emergent constraints, such as the one presented here, are invaluable as they can help to guide model development and, importantly, to speed up the provision of critical knowledge on expected future changes.

\section{Methods}

CMIP5/6 ensembles. Our ensembles (summarised in Supplementary Tables 1, 2) are based on 17 CMIP5 and 16 CMIP6 ESMs used in the Fifth and Sixth Assessment Report of the Intergovernmental Panel on Climate Change, respectively ${ }^{52}$. INM-CM4 has been excluded from our analysis because the model shows an outlying large density bias for both Intermediate Water (IW) and Mode Water $(\mathrm{MW})^{28}$. We use a single ensemble member (r1ilp1(f1) or equivalent) per model. The selected ESMs provide full periods of the following three standard CMIP5 (CMIP6) experiments: piControl, historical and RCP8.5 (SSP5-8.5). For our study, ocean $\mathrm{H}_{\text {excess }}$ uptake, ocean $\mathrm{C}_{\text {ant }}$ uptake and global atmospheric surface warming are calculated using the air-sea heat flux, the air-sea $\mathrm{CO}_{2}$ flux and the surface air temperature, respectively. The anthropogenic or excess component is obtained as the difference between the historical or future scenario and the preindustrial control experiments. Thus, $\mathrm{C}_{\text {ant }}$ and $\mathrm{H}_{\text {excess }}$ include changes induced by climate change (e.g. changes in ocean circulation, wind conditions, primary production).
} 
Latitudinal extent of the region considered for the constraint. In our study, we focus on the area where intermediate and mode waters are formed and subducted as these processes are the main drivers of ocean carbon and heat uptake in the Southern Ocean ${ }^{10,28,38}$. This area lies between $30^{\circ} \mathrm{S}$ and $55^{\circ} \mathrm{S}$ in all CMIP5 and CMIP6 models. The $30^{\circ} \mathrm{S}$ is a commonly used northern boundary for the Southern Ocean and its subduction region ${ }^{5,10,21}$. The $55^{\circ} \mathrm{S}$ southern boundary is chosen to exclude the influence of sea-ice on air-sea fluxes, which would complicate the uptake-stratification relationship (Supplementary Fig. 9). According to the CMIP5 and CMIP6 zonal wind stress distribution ${ }^{16}$, the $55^{\circ} \mathrm{S}$ southern boundary generally excludes the southward limb of the Southern Ocean overturning circulation, that is not related to the subduction process of interest in this study.

Density calculations and stratification index. We calculated in situ density $(\rho)$ from each ESM's potential temperature and practical salinity (after conversion to absolute salinity and conservative temperature) following TEOS-10 standards $s^{53}$. Three-dimensional $\rho$ fields have been area-weighted and averaged along horizontal surfaces to produce one-dimensional vertical profiles in native (model-dependent) vertical resolution.

We use a Stratification Index (SI) based on ref. 27 to characterise the stratification of the water column:

$$
\mathrm{SI}=\sum_{i=1}^{10} \rho^{z_{i}}-\rho^{z_{0}}
$$

where $z_{0}$ is the sea surface and $z_{i}=z_{i-1}+200$ for $i=1, \ldots, 10$

Probability density functions for the emergent constraints. The prior probability density functions for cumulative $\mathrm{C}_{\text {ant }}$ uptake and $\mathrm{H}_{\text {excess }}$ uptake efficiency assume that all models are equally likely to be correct and lead to a Gaussian distribution, and so is the probability density function of the observational constraint $P(x)^{21}$. The probability density function of the constrained estimate $P(y)$ was generated following established methodologies by normalising the product of the conditional probability density function of the emergent relationship $P(y \mid x)$ and the probability density function of the observational constraint $P(x): 21,22,25,26$

$$
P(y \mid x)=\frac{1}{\sqrt{2 \pi \sigma_{f}^{2}}} \exp \left\{\frac{(y-f(x))^{2}}{2 \sigma_{f}^{2}}\right\}
$$

where $x$ and $y$ are the predictor and the predictand, respectively. $\sigma_{f}=\sigma_{f}(x)$ and is the 'prediction error' of the emergent linear regression.

$$
P(y)=\int_{-\infty}^{+\infty} P\{y \mid x\} P(x) d x
$$

Observational constraint. The World Ocean Atlas 2013 version 2 (WOA13) annual climatology of $\rho$ (refs. ${ }^{54,55}$ ) is used as an observation-based estimate of the stratification index. The same horizontal area-weighting treatment as for the ESMs is applied to the three-dimensional $\rho$ field of WOA13 leading to a finer verticallyresolved (102 levels) one-dimensional vertical profile. $\rho$ anomaly profiles comparing the ESMs and WOA13 are computed by vertically interpolating the highresolution WOA13 $\rho$ profile to each coarsely-resolved model levels. The standard deviation of the WOA13 climatological monthly mean $\rho$ is used as a proxy for the uncertainty around the climatological mean, as such uncertainty is not provided in the WOA13 database ${ }^{26}$. Standard statistical formulas ${ }^{56}$ for uncertainty propagation are applied for the three-to-one-dimensional reduction.

The SI standard deviation $\left(\sigma_{\mathrm{SI}}\right)$ of the observational constraint is calculated from the SI formula:

$$
\sigma_{\mathrm{SI}}=\sqrt{\sum_{i=1}^{10} \overline{\sigma_{\rho^{z_{i}}}^{2}}+\overline{\sigma_{\rho^{z_{0}}}^{2}}}
$$

where $\sigma_{\rho^{z_{0}}}$ and $\sigma_{\rho^{z_{i}}}$ are the WOA13 standard deviations.

\section{Data availability}

CMIP5 and CMIP6 outputs are available from the Earth System Grid Federation (ESGF) portals (e.g. https://esgf-data.dkrz.de/). The WOA13 density climatology is available from the National Oceanographic Data Center portal (NODC/NOAA) under https:// www.nodc.noaa.gov/OC5/woa13/.

\section{Code availability}

The MATLAB environment was used for statistical processing, model analyses and figure creation. The Gibbs-SeaWater (GSW) Oceanographic Toolbox has been used to convert model sea potential temperature and practical salinity to conservative temperature and absolute salinity, and to calculate in situ density (http://www.teos-10.org/software.htm).

Received: 5 January 2021; Accepted: 21 December 2021; Published online: 17 January 2022

\section{References}

1. Manabe, S., Stouffer, R. J., Spelman, M. J. \& Bryan, K. Transient responses of a coupled ocean-atmosphere model to gradual changes of atmospheric $\mathrm{CO}_{2}$. Part I. Annual mean response. J. Climate 4, 785-818 (1991).

2. Khatiwala, S., Primeau, F. \& Hall, T. Reconstruction of the history of anthropogenic $\mathrm{CO}_{2}$ concentrations in the ocean. Nature 462, 346-349 (2009).

3. Tjiputra, J. F., Assmann, K. \& Heinze, C. Anthropogenic carbon dynamics in the changing ocean. Ocean Science 6, 605-614 (2010).

4. Ludicone, D. et al. Water masses as a unifying framework for understanding the Southern Ocean carbon cycle. Biogeosciences 8, 1031-1052 (2011).

5. Sallée, J.-B., Matear, R. J., Rintoul, S. R. \& Lenton, A. Localized subduction of anthropogenic carbon dioxide in the Southern Hemisphere oceans. Nat. Geosci. 5, 579-584 (2012).

6. Bopp, L., Lévy, M., Resplandy, L. \& Sallée, J.-B. Pathways of anthropogenic carbon subduction in the global ocean. J. Geophys. Res. 42, 6416-6423 (2015).

7. Meijers, A. J. S. The Southern Ocean in the coupled model intercomparison project phase 5. Phil. Trans. R. Soc. A 372, 20130296 (2014).

8. Le Quéré, C. et al. Saturation of the Southern Ocean $\mathrm{CO}_{2}$ sink due to recent climate change. Science 316, 1735-1738 (2007).

9. Anderson, R. F. et al. Wind-driven upwelling in the Southern Ocean and the deglacial rise in atmospheric $\mathrm{CO}_{2}$. Science 323, 1443-1448 (2009).

10. Frölicher, T. L. et al. Dominance of the Southern Ocean in anthropogenic carbon and heat uptake in CMIP5 models. J. Climate 28, 862-886 (2015).

11. Kessler, A. \& Tjiputra, J. The Southern Ocean as a constraint to reduce uncertainty in future ocean carbon sinks. Earth Sys. Dyn. 7, 295-312 (2016).

12. Sallée, J.-B. Southern Ocean warming. Oceanography 31, 52-62 (2018).

13. Downes, S. M. \& Hogg, A. M. C. C. Southern Ocean circulation and Eddy compensation in CMIP5 models. J. Climate 26, 7198-7220 (2013).

14. Sallée, J.-B. et al. Assessment of Southern Ocean mixed-layer depths in CMIP5 models: historical bias and forcing response. J. Geophys. Res. Ocean. 118, 1845-1862 (2013)

15. Mongwe, N. P., Vichi, M. \& Monteiro, P. M. S. The seasonal cycle of $\mathrm{pCO}_{2}$ and $\mathrm{CO}_{2}$ fluxes in the Southern Ocean: diagnosing anomalies in CMIP5 Earth system models. Biogeosciences 15, 2851-2872 (2018).

16. Beadling, R. L. et al. Representation of Southern Ocean properties across coupled model intercomparison project generations: CMIP3 to CMIP6. J. Climate 33, 6555-6581 (2020).

17. Rogelj, J. et al. Energy system transformations for limiting end-of-century warming to below $1.5^{\circ} \mathrm{C}$. Nat. Clim. Chang. 5, 519-527 (2015).

18. Rogelj, J., Forster, P. M., Kriegler, E., Smith, C. J. \& Séférian, R. Estimating and tracking the remaining carbon budget for stringent climate targets. Nature 571, 335-342 (2019).

19. Hall, A. \& Qu, X. Using the current seasonal cycle to constrain snow albedo feedback in future climate change. Geophys. Res. Lett. 33, L03502 (2006).

20. Hall, A., Cox, P., Huntingford, C. \& Klein, S. Progressing emergent constraints on future climate change. Nat. Clim. Chang. 9, 269-278 (2019).

21. Cox, P. M. et al. Sensitivity of tropical carbon to climate change constrained by carbon dioxide variability. Nature 494, 341-344 (2013).

22. Wenzel, S., Cox, P. M., Eyring, V. \& Friedlingstein, P. Emergent constraints on climate-carbon cycle feedbacks in the CMIP5 Earth system models. J. Geophys. Res.: Biogeosciences 119, 794-807 (2014).

23. Wenzel, S., Cox, P. M., Eyring, V. \& Friedlingstein, P. Projected land photosynthesis constrained by changes in the seasonal cycle of atmospheric $\mathrm{CO}_{2}$. Nature 538, 499-501 (2016).

24. Goris, N. et al. Constraining projection-based estimates of the future North Atlantic carbon uptake. J. Climate 31, 3959-3978 (2018).

25. Kwiatkowski, L. et al. Emergent constraints on projections of declining primary production in the tropical oceans. Nat. Clim. Chang. 7, 355-358 (2017).

26. Terhaar, J., Kwiatkowski, L. \& Bopp, L. Emergent constraint on Arctic Ocean acidification in the twenty-first century. Nature 582, 379-383 (2020).

27. Sgubin, G., Swingedouw, D., Drijfhout, S., Mary, Y. \& Bennabi, A. Abrupt cooling over the North Atlantic in modern climate models. Nat. Commun. 8, 14375 (2017)

28. Sallée, J. B. et al. Assessment of Southern Ocean water mass circulation and characteristics in CMIP5 models: Historical bias and forcing response. $J$. Geophys. Res. Ocean. 118, 1830-1844 (2013).

29. Mignone, B. K., Gnanadesikan, A., Sarmiento, J. L. \& Slater, R. D. Central role of Southern Hemisphere winds and eddies in modulating the oceanic uptake of anthropogenic carbon. Geophys. Res. Lett. 33, (2006)

30. Gregory, J. M. \& Mitchell, J. F. B. The climate response to $\mathrm{CO}_{2}$ of the Hadley Centre coupled AOGCM with and without flux adjustment. Geophys. Res. Lett. 24, 1943-1946 (1997).

31. Andrews, T., Gregory, J. M., Webb, M. J. \& Taylor, K. E. Forcing, feedbacks and climate sensitivity in CMIP5 coupled atmosphere-ocean climate models. Geophys. Res. Lett. 39, 1-7 (2012). 
32. Williams, R. G., Ceppi, P. \& Katavouta, A. Controls of the transient climate response to emissions by physical feedbacks, heat uptake and carbon cycling. Environ. Res. Lett. 15, 0940c1 (2020).

33. Yoshimori, M. et al. A review of progress towards understanding the transient global mean surface temperature response to radiative perturbation. Prog. Earth Planet. Sci. 3, 21 (2016).

34. Meinshausen, M. et al. The shared socio-economic pathway (SSP) greenhouse gas concentrations and their extensions to 2500. Geosci. Model Dev. 13, 3571-3605 (2020).

35. Schlund, M., Lauer, A., Gentine, P., Sherwood, S. C. \& Eyring, V. Emergent constraints on equilibrium climate sensitivity in CMIP5: do they hold for CMIP6? Earth Sys. Dyn. 11, 1233-1258 (2020).

36. Sanderson, B. M., Knutti, R. \& Caldwell, P. A representative democracy to reduce interdependency in a multimodel ensemble. J. Clim. 28, 5171-5194 (2015).

37. Sanderson, B. M. et al. The potential for structural errors in emergent constraints. Earth Sys. Dyn. 12, 899-918 (2021).

38. Sabine, C. L. The oceanic sink for anthropogenic $\mathrm{CO}_{2}$. Science 305, 367-371 (2004).

39. Williams, R. G. Ocean Subduction. In Encyclopedia of Ocean Sciences (ed. Steele, J. H.) 1982-1993 (Academic press, 2001).

40. Li, Z., England, M. H., Groeskamp, S., Cerovečki, I. \& Luo, Y. The origin and fate of subantarctic mode water in the Southern Ocean. J. Phys. Oceanogr. 58, 2951-2972 (2021).

41. Kuhlbrodt, T. \& Gregory, J. M. Ocean heat uptake and its consequences for the magnitude of sea level rise and climate change. Geophys. Res. Lett. 39, L18608 (2012).

42. Bronselaer, B. \& Zanna, L. Heat and carbon coupling reveals ocean warming due to circulation changes. Nature 584, 227-233 (2020).

43. Banks, H. T. \& Gregory, J. M. Mechanisms of ocean heat uptake in a coupled climate model and the implications for tracer based predictions of ocean heat uptake. Geophys. Res. Lett. 33, L07608 (2006).

44. Xie, P. \& Vallis, G. K. The passive and active nature of ocean heat uptake in idealized climate change experiments. Clim. Dyn. 38, 667-684 (2012).

45. Winton, M. et al. Connecting changing ocean circulation with changing climate. J. Clim. 26, 2268-2278 (2013).

46. Williams, R. G., Katavouta, A. \& Roussenov, V. Regional asymmetries in ocean heat and carbon storage due to dynamic redistribution in climate model projections. J. Clim. 34, 3907-3925 (2021).

47. Fu, W., Randerson, J. T. \& Moore, J. K. Climate change impacts on net primary production (NPP) and export production (EP) regulated by increasing stratification and phytoplankton community structure in the CMIP5 models. Biogeosciences 13, 5151-5170 (2016).

48. Eyring, V. et al. Taking climate model evaluation to the next level. Nat. Clim. Chang. 9, 102-110 (2019).

49. Terhaar, J., Frölicher, T. L. \& Joos, F. Southern Ocean anthropogenic carbon sink constrained by sea surface salinity, Sci. Adv. 7, eabd5964 (2021).

50. Rackow, T. et al. Sensitivity of deep ocean biases to horizontal resolution in prototype CMIP6 simulations with AWI-CM1.0. Geosci. Model Dev. 12, 2635-2656 (2019).

51. Mak, J., Maddison, J. R., Marshall, D. P. \& Munday, D. R. Implementation of a geometrically informed and energetically constrained mesoscale Eddy parameterization in an ocean circulation model. J. Phys. Oceanogr. 48, 2363-2382 (2018).

52. Flato, G. et al. In Climate Change 2013: The Physical Science Basis. Contribution of Working Group I to the Fifth Assessment Report of the Intergovernmental Panel on Climate Change (eds. Stocker, T. F. et al.) (Cambridge Univ. Press, 2013).

53. Feistel, R. A Gibbs function for seawater thermodynamics for -6 to $80{ }^{\circ} \mathrm{C}$ and salinity up to $120 \mathrm{gkg}-1$. Deep Sea Res. Part I 55, 1639-1671 (2008).

54. Locarnini, R. A. et al. World Ocean Atlas 2013, Volume 1: Temperature. NOAA Atlas NESDIS 73, 40, https://www.nodc.noaa.gov/OC5/WOD13/ (2013).
55. Zweng, M. M. et al. World Ocean Atlas 2013, Volume 2: Salinity. NOAA Atlas NESDIS 74, 39, https://www.nodc.noaa.gov/OC5/WOD13/ (2013).

56. BIPM. Evaluation of measurement data: Guide to the expression of uncertainty in measurement (JCGM 100:2008, GUM 1995 with minor corrections) (2008).

\section{Acknowledgements}

We acknowledge the World Climate Research Programme, which, through its Working Group on Coupled Modelling, coordinated and promoted CMIP. We thank the climate modelling groups for producing and making available their model output, the Earth System Grid Federation (ESGF) for archiving the data and providing access, and the multiple funding agencies who support CMIP and ESGF. All authors received funding from the Research Council of Norway (RCN) under grant No. 275268 (COLUMBIA) and from the European Union's Horizon 2020 research and innovation programme under grant agreement No. 820989 (COMFORT). The work reflects only the authors' view; the European Commission and their executive agency are not responsible for any use that may be made of the information the work contains. J.S. and J.F.T. also received support from the RCN under grant No. 295046 (KeyCLIM) and 318477 (CE2COAST). We thank J. Terhaar for productive discussions. The analysis was made possible through the resources provided by UNINETT Sigma2-the National Infrastructure for data Storage in Norway (project NS9252K).

\section{Author contributions}

T.B. performed all calculations and carried out the analysis. T.B., N.G., J.S. and J.F.T. were heavily involved in designing the analysis, interpreting the results and writing the manuscript.

\section{Competing interests}

The authors declare no competing interests.

\section{Additional information}

Supplementary information The online version contains supplementary material available at https://doi.org/10.1038/s41467-022-27979-5.

Correspondence and requests for materials should be addressed to Timothée Bourgeois

Peer review information Nature Communications thanks Paul Halloran, Stephen Rintoul and Richard Williams for their contribution to the peer review of this work.

Reprints and permission information is available at http://www.nature.com/reprints

Publisher's note Springer Nature remains neutral with regard to jurisdictional claims in published maps and institutional affiliations.

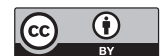

Open Access This article is licensed under a Creative Commons Attribution 4.0 International License, which permits use, sharing, adaptation, distribution and reproduction in any medium or format, as long as you give appropriate credit to the original author(s) and the source, provide a link to the Creative Commons license, and indicate if changes were made. The images or other third party material in this article are included in the article's Creative Commons license, unless indicated otherwise in a credit line to the material. If material is not included in the article's Creative Commons license and your intended use is not permitted by statutory regulation or exceeds the permitted use, you will need to obtain permission directly from the copyright holder. To view a copy of this license, visit http://creativecommons.org/ licenses/by/4.0/.

(c) The Author(s) 2022 